\title{
Temperature Dependence of Electrical Properties of Organic Thin Film Transistors Based on pn Heterojuction and Their Applications in Temperature Sensors
}

\author{
Rongbin Ye, Koji Ohta, Mamoru Baba \\ Faculty of Engineering, Iwate University, Morioka, Japan \\ Email: ye@iwate-u.ac.jp
}

Received 22 February 2016; accepted 19 May 2016; published 26 May 2016

\begin{abstract}
Organic thin film transistors based on an $\mathrm{F}_{16} \mathrm{CuPc} / \alpha 6 \mathrm{~T}$ pn heterojunction have been fabricated and analyzed to investigate the temperature dependence of electrical properties and apply in temperature sensors. The mobility follows a thermally activated hopping process. At temperatures over $200 \mathrm{~K}$, the value of thermal activation energy $\left(E_{A}\right)$ is $40.1 \mathrm{meV}$, similar to that of the single-layer device. At temperatures ranging from 100 to $200 \mathrm{~K}$, we have a second regime with a much lower $E_{A}$ of $16.3 \mathrm{meV}$, where the charge transport is dominated by shallow traps. Similarly, at temperatures above $200 \mathrm{~K}$, threshold voltage $\left(V_{T}\right)$ increases linearly with decreasing temperature, and the variations of $V_{T}$ of $0.185 \mathrm{~V} / \mathrm{K}$ is larger than the variation of $V_{T}(\sim 0.020 \mathrm{~V} / \mathrm{K})$ in the single layer devices. This result is due to the interface dipolar charges. At temperatures ranging from $100 \mathrm{~K}$ to $200 \mathrm{~K}$, we have a second regime with much lower variations of $0.090 \mathrm{~V} / \mathrm{K}$. By studying gate voltage $\left(V_{G}\right)$-dependence temperature variation factor $(k)$, the maximum value of $k(\sim 0.11$ $\mathrm{dec} / \mathrm{K}$ ) could be obtained at $V_{G}=5 \mathrm{~V}$. Furthermore, the pn heterojunction device could be characterized as a temperature sensor well working at low operating voltages.
\end{abstract}

\section{Keywords}

Organic Thin Film Transistors, pn Heterojunction, Temperature Dependence, Temperature Sensors

\section{Introduction}

Organic Thin Film Transistors (OTFTs) offer a promising technology for low-cost large-area electronic applications such as active-matrix displays, electronic papers, flexible microelectronics and physical or chemical sensor arrays [1]-[3]. It has been known that temperature is an important physical parameter that is often measured and thermal sensors have a lot of application potentials. The need for reliable, inexpensive and harmless temperature sensors that can be operated simply is also a concern for electronic skins, electronic health monitoring, and de- 
tecting patients' body temperatures. However, OTFT-based temperature sensing devices are very sensitive towards a small change in temperature and usually work at highly operating voltages [4]. It is natural that employment of high-k dielectric is one of the most important strategies to reduce operating voltage of OTFT devices [3].

On the other hand, we have reported a kind of organic pn heterojunctions, in which high density of carriers formed a conduction channel at interface [5]-[10]. Ambipolar transport is dependence of the first active layer thickness ( $\mathrm{F}_{16} \mathrm{CuPc}$, fluorinated copper phthalocyanine) in an $\mathrm{F}_{16} \mathrm{CuPc} / \mathrm{CuPc}$ (copper phthalocyanine) heterojunction, and only n-channel operation is observed when $\mathrm{F}_{16} \mathrm{CuPc}$ films are over a critical thickness of $\sim 12 \mathrm{~nm}$. We have also investigated the temperature dependence of electrical properties of ambipolar OTFTs based on $\mathrm{F}_{16} \mathrm{CuPc} / \alpha 6 \mathrm{~T}$ (sexithiophene) pn heterojunction, which hints that the pn heterojunction device has a potential use as a temperature sensor working at low operating voltages without dielectric engineering [9] [10]. In this study, we report on temperature dependence of electrical properties of OTFTs based on $\mathrm{F}_{16} \mathrm{CuPc} / \alpha 6 \mathrm{~T}$ pn heterojuction only working at n-channel and their applications in temperature sensors.

\section{Experimental Details}

The device configurations are shown in Figure 1. Frist, a top-contact $\mathrm{F}_{16} \mathrm{CuPc}$ TFT was fabricated. A heavily n-doped Si substrate acts as the gate electrode with a $300 \mathrm{~nm}$ thermally grown $\mathrm{SiO}_{2}$ layer $\left(\mathrm{C}_{\mathrm{i}} \sim 10 \mathrm{nF} / \mathrm{cm}^{2}\right)$ as the gate dielectric. $\mathrm{F}_{16} \mathrm{CuPc}$ thin films of $20 \mathrm{~nm}$ were vacuum-deposited and the substrate temperature was set at $120^{\circ} \mathrm{C}$. Au source and drain electrodes of approximately $50 \mathrm{~nm}$ were vacuum-deposited through a shadow mask with a channel width of $5 \mathrm{~mm}$ and a length of $70 \mu \mathrm{m}$. Then, $\alpha 6 \mathrm{~T}$ thin films were vacuum-deposited on the above-mentioned $\mathrm{F}_{16} \mathrm{CuPc}$ device at room temperature. The characteristics of the device were in-situ measured with a two-channel voltage current source/monitor system (R6245, ADVANTEST) at $\alpha 6 \mathrm{~T}$ film thicknesses of 0 , 1, 2, 3, 5, 7 10, 15 and $20 \mathrm{~nm}$, respectively, controlled by a shutter. All films were deposited under a base pressure of less than $1 \times 10^{-3} \mathrm{~Pa}$, and thicknesses and growth rates were monitored by a thickness and rate monitor (CRTM-6000, ULVAC). Temperature dependence of electrical characteristics of these devices were measured with R6245 in a cryostat (E202C5L, DAIKIN), which was temperature-controlled from $300 \mathrm{~K}$ to $100 \mathrm{~K}$ through a cryocooler using a He-gas flowing method.

\section{Results and Discussion}

Figure 2(a) shows output characteristics of a sandwich device with $\alpha 6 \mathrm{~T}$ thin films of $0 \mathrm{~nm}$ (namely, the topcontact $\mathrm{F}_{16} \mathrm{CuPc}$ TFT), which typically works in an n-channel operational mode. The linear and saturation regions can be observed with the increases of drain voltage $\left(V_{D}\right)$ and gate voltage $\left(V_{G}\right)$. Figure 2(b) shows the same for the sandwich device when $\alpha 6 \mathrm{~T}$ thin films of $20 \mathrm{~nm}$ were deposited. We observe a dramatic difference in the shape and magnitude of the drain current $\left(I_{D}\right)$. In the sandwich device $\mathrm{I}_{\mathrm{D}}$ is up to $15.2 \mu \mathrm{A}$ at $V_{G}$ and $V_{D}$ of $60 \mathrm{~V}$ and does not saturate. Furthermore, a large bulk current in the sandwich device at $V_{G}=0 \mathrm{~V}$ could also be observed, which originates from the charge carriers at the interface of $\mathrm{F}_{16} \mathrm{CuPc} / \alpha 6 \mathrm{~T}$ [5]-[10]. Figure 2(c) shows characteristics of the sandwich device with various thicknesses of $\alpha 6 \mathrm{~T}$ thin films. Mobility $\left(\mu_{n}\right)$ and threshold voltage $\left(V_{T}\right)$ were extracted in the linear region as followed [11]:

$$
I_{D}=(W / L) C_{i} \mu_{n}\left(V_{G}-V_{T}\right) V_{D}\left(V_{G} \gg V_{D}\right),
$$

where $W, L$, and $C_{i}$ are the channel width, channel length, and gate dielectric capacitance per unit area, respectively.

(a)

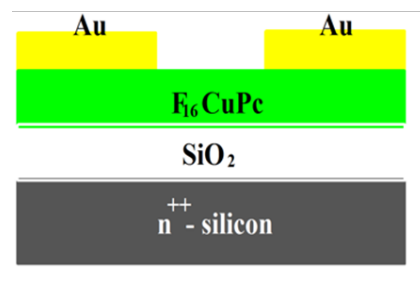

(b)



Figure 1. Schematic cross sections of (a) a single layer and (b) a sandwich device (the dimensions are not scaled). 
The dependence of $\mu / \mu_{0}$ and $V_{T}$ shift ( $\Delta V_{T}$ ) on the thickness of $\alpha 6 \mathrm{~T}$ are shown in Figure 2(d). Obviously, $V_{T}$ undergoes a significant shift from +27.13 to $+18.10 \mathrm{~V}$ with increasing the thickness of $\alpha 6 \mathrm{~T}$. When the thickness of $\alpha 6 \mathrm{~T}$ is more than a critical thickness of $5-7 \mathrm{~nm}, V_{T}$ undergoes hardly any shift. On the other hand, the values of $\mu_{n}$ is lightly decreased with increasing the thickness of $\alpha 6 \mathrm{~T}$ due to the effect of the bulk current. Thus the $\Delta V_{T}$ attributes to the increase of $I_{D}$ in the sandwich device. It has been known that the bulk current results the organic pn heterojunction interface dipolar, and the electrons and holes are free charges, which are significantly distinguished from ionized impurities, localized in the space charge region for convention inorganic pn junctions, and $\left|\Delta V_{T}\right|$ is a $\tan ^{-1}$ function of film thickness $(t)$ and expressed as following [12]:

$$
\left|\Delta V_{T}\right|=\left(Q_{0} / C_{i}\right) \tan ^{-1}\left(t / W_{d}\right),
$$

where $Q_{0}$ and $w_{d}$ are the total charges density and the full width at half maximum, respectively. The blue dotted line in Figure 4(d) is fitted to Equation (2), yielding $w_{d}$ and $Q_{0}$ of $3.2 \mathrm{~nm}$ and $6.84 \times 10^{-8} \mathrm{C} / \mathrm{cm}^{2}$ $\left(4.28 \times 10^{11}\right.$ electrons or holes $\left./ \mathrm{cm}^{2}\right)$, respectively. The value of $w_{d}$ is in complete agreement with half of the critical thickness of $5-7 \mathrm{~nm}$.

Figure 3(a) and Figure 3(b) show transfer characteristics of another $\mathrm{F}_{16} \mathrm{CuPc} / \alpha 6 \mathrm{~T}$ TFT in the linear regions at different temperatures. $I_{D}$ decrease as the temperature is lowered. Using Equation (1), $\mu_{n}$ and $V_{T}$ were evaluated from the local slopes of the transfer characteristics in the linear regions. As shown in Figure 3(c), the temperature dependence of mobility can be divided into two regions, and the mobility are clearly thermally activated with thermal activation energy $E_{a}$, which was calculated by Arrhenius behavior as $\mu \propto \exp \left(-E_{a} / k_{B} T\right)$ [9]. At temperatures over $200 \mathrm{~K}$, the value of $E_{a}$ is $40.1 \mathrm{meV}$, similar to that of the single layer device [13]. At temperatures ranging from 100 to $200 \mathrm{~K}$, we have a second regime with a much lower $E_{a}$ of $16.3 \mathrm{meV}$, where the charge transport is dominated by shallow traps. The temperature dependence of $V_{T}$ for the pn heterojunction device is given in Figure 3(d). At temperatures above $200 \mathrm{~K}, V_{T}$ increases linearly with decreasing temperature. The variation of $V_{T}$ of $0.185 \mathrm{~V} / \mathrm{K}$ is larger than the variation of $V_{T}(\sim 0.02 \mathrm{~V} / \mathrm{K})$ in the single


Figure 2. Output characteristics of a sandwich $\mathrm{F}_{16} \mathrm{CuPc} / \alpha 6 \mathrm{~T}$ TFT with $\alpha 6 \mathrm{~T}$ thin films of (a) $0 \mathrm{~nm}$ and (b) $20 \mathrm{~nm}$, (c) transfer characteristics of the sandwich device with various thicknesses of $\alpha 6 \mathrm{~T}$ thin films in the linear regions, and (d) dependence of $\left|\Delta V_{T}\right|$ and $\mu / \mu_{0}$ on the thicknesses of $\alpha 6 \mathrm{~T}$ thin films, respectively. 

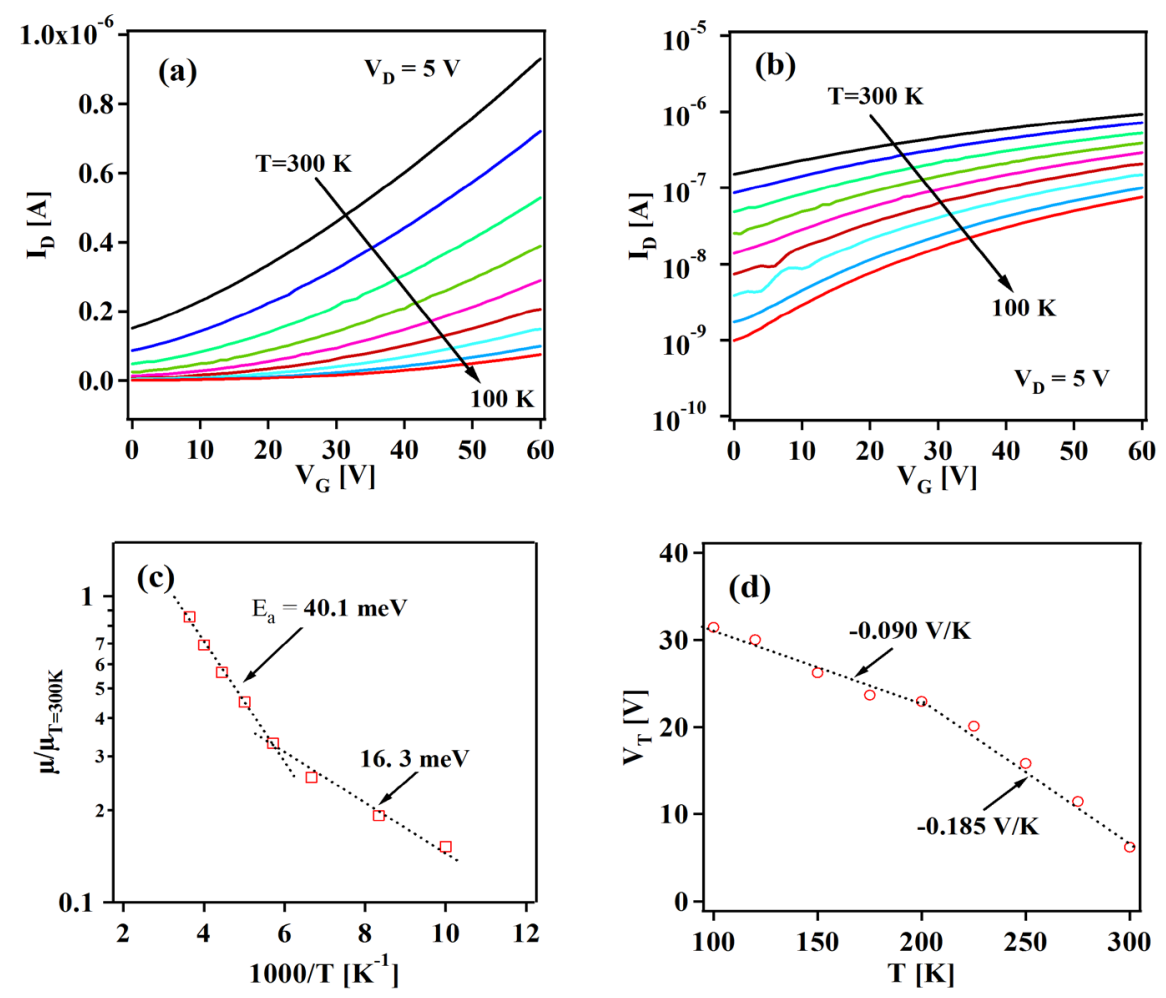

Figure 3. (a) (b) Transfer characteristics of another $\mathrm{F}_{16} \mathrm{CuPc} / \alpha 6 \mathrm{~T}$ TFT in the linear regions at different temperatures, temperature dependence of (c) mobility and (d) threshold voltage of the sandwich $\mathrm{F}_{16} \mathrm{CuPc} / \alpha 6 \mathrm{~T}$ TFT, respectively.

layer device [13]. This result is due to the interface dipolar charges [12]. At temperatures ranging from $100 \mathrm{~K}$ to $200 \mathrm{~K}$, we have a second regime with much lower variation of $0.090 \mathrm{~V} / \mathrm{K}$.

Figure 4(a) shows plots of $\log \left(I_{D}\right)$ as a function of temperature at different $V_{G}$ from Figure 3(b), which can be analyzed by Equation (3) as following:

$$
\log \left(I_{D}\right)=k^{*} T+c_{0},
$$

where $k$ is a $V_{G}$-dependent temperature variation factor, $d / d T\left(\log \left(I_{D}\right)\right)$. Using Equation (3), $k$ can be calculated for each $V_{G}$, and the result is summarized and shown in Figure 4(b). Increasing $V_{G}, k$ increases, and then $k$ decreases when $V_{G}>5 \mathrm{~V}$. The maximum value of $k(\sim 0.11 \mathrm{dec} / \mathrm{K})$ could be obtained at $V_{G}=5 \mathrm{~V}$. On the other hand, $I_{D}$ at low $V_{D}$ and $V_{G}$ is comparable to that at high $V_{D}$ and $V_{G}$ unlike a single layer device. Thus the pn heterojunction device could be characterized as a temperature sensor working at low $V_{D}$ and $V_{G}$.

Figure 5(a) shows electrical response of a sandwich $\mathrm{F}_{16} \mathrm{CuPc} / \alpha 6 \mathrm{~T}$ TFT biased at $V_{D}=V_{G}=5 \mathrm{~V}$ to temperature cycles, and the measured output current shows over three times of magnitude increase from $8.91 \times 10^{-8}$ to $2.83 \times 10^{-7}$ A when the temperature increases from 250 to $300 \mathrm{~K}$. As shown in Figure 5(b), the $\log \left(I_{s}\right)$ linearly depends on temperatures, and $k=9.26 \times 10^{-3} \mathrm{dec} / \mathrm{K}$ could be obtained when being fitted with Equation (3); this well corresponds to the above-mentioned data. This result shows that the pn heterojunction device may successfully be used as temperature sensing components.

\section{Conclusion}

In this paper, we report on temperature dependence of electrical properties of OTFTs based on an $\mathrm{F}_{16} \mathrm{CuPc} / \alpha 6 \mathrm{~T}$ pn heterojunction and their applications in temperature sensors. The mobility follows a thermally activated hopping process. At temperatures over $200 \mathrm{~K}$, the value of $E_{A}$ is $40.1 \mathrm{meV}$, similar to that of the single layer device. At temperatures ranging from 100 to $200 \mathrm{~K}$, we have a second regime with a much lower $E_{A}$ of $16.3 \mathrm{meV}$, where the charge transport is dominated by shallow traps. Similarly, at temperatures above $200 \mathrm{~K}, V_{T}$ increases linearly 

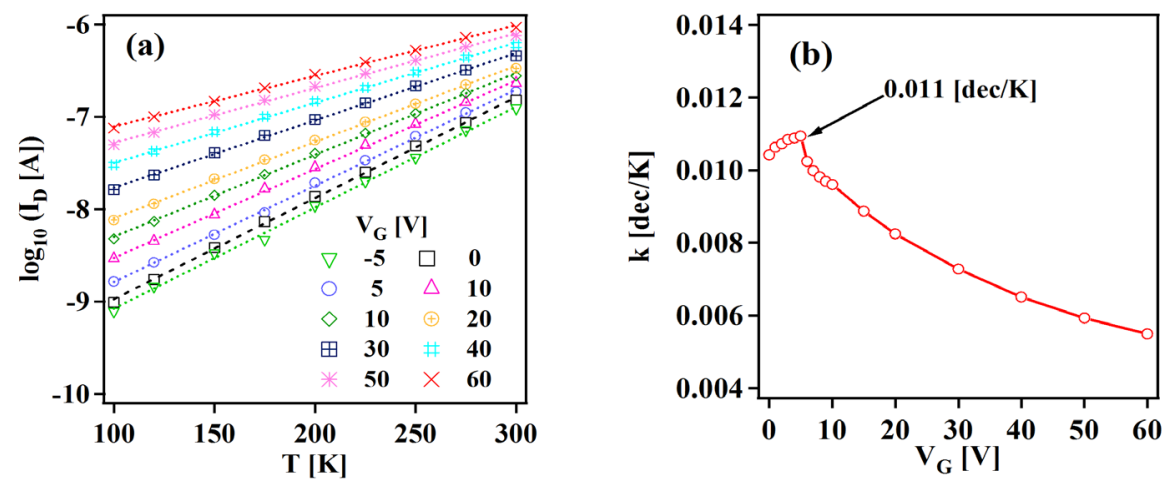

Figure 4. (a) $V_{G}$ dependence of $\log _{10}\left(I_{D}\right)$ on the temperatures, and (b) dependence of $k$ on $V_{G}$.
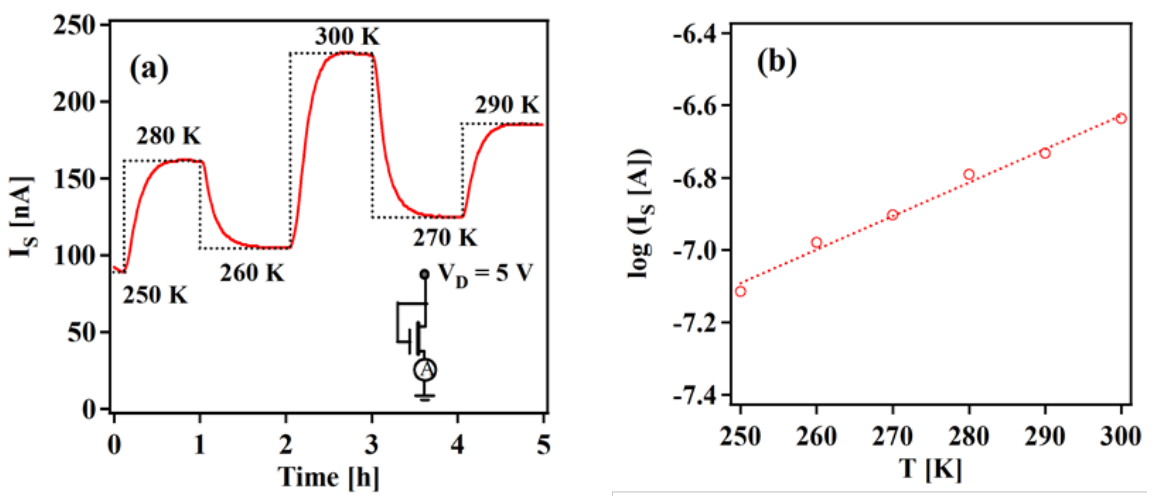

Figure 5. (a) Electrical response of source current $\left(I_{S}\right)$ of a sandwich $\mathrm{F}_{16} \mathrm{CuPc} / \alpha 6 \mathrm{~T}$ TFT to temperature cycles, and (b) $\log _{10}\left(I_{S}\right)$ temperature dependence of the sandwich device. The inset of Figure 5(a) shows the circuit diagrams of temperature sensor working at $V_{D}=V_{G}=5 \mathrm{~V}$.

with decreasing temperature, and the variation of $V_{T}$ of $0.185 \mathrm{~V} / \mathrm{K}$ is larger than the variation of $V_{T}(\sim 0.02 \mathrm{~V} / \mathrm{K})$ in the single layer device. This result is due to the interface dipolar charges. At temperatures ranging from $100 \mathrm{~K}$ to $200 \mathrm{~K}$, we have a second regime with much lower variation of $0.090 \mathrm{~V} / \mathrm{K}$. By studying $V_{G}$ dependence of $\log _{10}\left(I_{D}\right)$ on the temperatures, the maximum value of $k(\sim 0.11 \mathrm{dec} / \mathrm{K})$ could be obtained at $V_{G}=5 \mathrm{~V}$. Furthermore, the pn heterojunction device could be characterized as a temperature sensor well working at low $V_{D}$ and $V_{G}$.

\section{References}

[1] Logothetidis, S. (2015) Handbook of Flexible Organic Electronics-Materials, Manufacturing and Applications. Woodhead Publishing, UK.

[2] Bernards, D.A., Owens, R.M. and Malliaras, G.G. (2008) Organic Semiconductors in Sensor Applications. SpringerVerlag Berlin Heidelberg.

[3] Bao, Z. and Locklin, J. (2007) Organic Field-Effect Transistors. CRC Press, UK. http://dx.doi.org/10.1201/9781420008012

[4] Someya, T., Kato, Y., Sekitani, T., Iba, S., Noguchi, Y., Murase, Y., Kawaguchi, H. and Sakurai, T. (2005) Conformable, Flexible, Large-Area Networks of Pressure and Thermal Sensors with Organic Transistor Active Matrixes. Proceedings of the National Academy of Sciences of the United States of America, 102, 12321. http://dx.doi.org/10.1073/pnas.0502392102

[5] Ye, R., Baba, M., Oishi, Y., Mori, K. and Suzuki, K. (2005) Air-Stable Ambipolar Organic Thin-Film Transistors Based on an Organic Homostructure. Applied Physics Letters, 86, 253505. http://dx.doi.org/10.1063/1.1949731

[6] Ye, R., Baba, M. and Mori, K. (2005) High-Performance Air-Stable Ambipolar Organic Thin-Film Transistor Based on F16CuPc and CuPc. Japanese Journal of Applied Physics, 44, L581. http://dx.doi.org/10.1143/jiap.44.1581

[7] Ye, R., Baba, M., Mori, K. and Suzuki, K. (2007) Dependence of Ambipolar Transport on First Active Layer Thick- 
ness in Organic Homostructure Transistors. Japanese Journal of Applied Physics, 46, 2878. http://dx.doi.org/10.1143/JJAP.46.2878

[8] Ye, R., Baba, M., Mori, K. and Suzuki, K. (2009) Improved Performance of Fluorinated Copper Phthalocyanine Thin Film Transistors Using an Organic pn Junction: Effect of Copper Phthalocyanine Film Thickness. Thin Solid Films, 517, 3001-3004. http://dx.doi.org/10.1016/j.tsf.2008.11.104

[9] Ye, R., Baba, M., Ohta, K., Mori, K. and Suzuki, K. (2010) Temperature Dependence of Electrical Properties of Ambipolar Organic Transistors Based on F16CuPc/ $\alpha$-Sexithiophene p-n Heterojunction. Japanese Journal of Applied Physics, 49, 04DK02. http://dx.doi.org/10.1143/JJAP.49.04DK02

[10] Ye, R., Baba, M., Ohta, K., Suzuki, T. and Mori, K. (2011) The Meyer-Neldel Rule in Ambipolar Organic Thin Film Transistors Based on F16CuPc/a6T pn Heterojunction. Physica Status Solidi (C), 8, 598. http://dx.doi.org/10.1002/pssc.201000372

[11] Sze, S.M. (1981) Physics of Semiconductor Devices, Wiley, New York.

[12] Ye, R., Ohta, K. and Baba, M. (2014) In-Situ Study of pn-Heterojunction Interface States in Organic Thin Film Transistors. Thin Solid Films, 554, 137-140. http://dx.doi.org/10.1016/j.tsf.2013.05.057

[13] Ye, R., Baba, M., Ohishi, Y., Mori, K. and Suzuki, K. (2006) On the Correlation between Morphology and Electronic Properties of Fluorinated Copper Phthalocyanine (F16CuPc) Thin Films. Molecular Crystals and Liquid Crystals, 444, 203-210. http://dx.doi.org/10.1080/15421400500364972 